\title{
Assessing sustainability and improvements in US Midwestern soybean production systems using a PCA-DEA approach
}

\author{
Fengxia Dong ${ }^{1 \star}$, Paul D. Mitchell ${ }^{2}$, Deana Knuteson ${ }^{3}$, Jeffery Wyman ${ }^{4}$, A.J. Bussan ${ }^{3}$ and \\ Shawn Conley ${ }^{5}$ \\ 'Department of Agricultural and Applied Economics, University of Wisconsin, 427 Lorch Street, Madison WI 53706, \\ USA. \\ ${ }^{2}$ Department of Agricultural and Applied Economics, Co-Director Nutrient and Pest Management Program, \\ University of Wisconsin, 427 Lorch Street, Madison, WI 53706, USA. \\ ${ }^{3}$ Department of Horticulture, University of Wisconsin, 1575 Linden Drive, Madison, WI 53706, USA. \\ ${ }^{4}$ Department of Entomology, University of Wisconsin, 1630 Linden Drive, Madison, WI 53706, USA. \\ Department of Agronomy, University of Wisconsin, 1575 Linden Drive, Madison, WI 53706, USA. \\ ${ }^{*}$ Corresponding author: fdong6@wisc.edu
}

Accepted 14 October 2015; First published online 20 November 2015

Research Paper

\begin{abstract}
Documentation of on-farm sustainability in agricultural sectors is becoming an essential element to ensure market access. An assessment process was developed to help soybean farmers document practices and verifiable advances in community, environmental and economic sustainability. Technical difficulties in analyzing and summarizing such assessment data include a large number of practices, correlation in variables, and use of discrete measures. By combining nonnegative principal components analysis and common-weight data envelopment analysis, we overcame these difficulties to calculate a composite sustainability index for each individual farm and for the farm group as a whole. Applying this method to assessment data from 410 US Midwestern soybean farmers gave average sustainability scores of 0.846 and 0.842 for the soybean-specific and whole-farm assessments, respectively. Scenario analysis examined the impact if the bottom $10 \%$ of growers adopted the top ten sustainability drivers identified by the analysis. The average sustainability score only increased by $2 \%$, but the minimum score increased from 0.515 to 0.647 for the soybean-specific assessment, and from 0.624 to 0.685 for the whole-farm assessment, while the lowest 10th percentile increased from 0.635 to 0.819 for the soybean-specific assessment, and from 0.634 to 0.920 for the whole-farm assessment. These results suggest that significant advancements could be made through focused efforts to improve adoption of sustainable practices by soybean farmers at the lower end of the spectrum.
\end{abstract}

Key words: sustainability assessment, soybean production, non-negative principal component analysis, common-weight data envelopment analysis

\section{Introduction}

While agricultural productivity has increased dramatically over the last half-century, meeting current and projected world food demand in a sustainable manner will be a major challenge for agriculture while facing global climate change (Beddington et al., 2012). In this context, sustainable agriculture continues to garner interest and increased investment in sustainability and agricultural intensification will be part of the response (Beddington et al., 2012; Garnett et al., 2013; Sustainable Agriculture Research and Education Program, 2015).
Though many definitions of agricultural sustainability exist, most of them rest on the principle that developments must meet the needs of the present without compromising the ability of future generations to meet their own needs (United Nations, 1987; Gliessman, 1998; The Royal Society, 2009; Sustainable Agriculture Research and Education Program, 2015). There seems to be a growing consensus that agricultural sustainability addresses three dimensions: environmental, economic and social (Francis and Youngberg, 1990; Sustainable Agriculture Research and Education, 1997; National Research Council, 2010; Sustainable Agriculture 


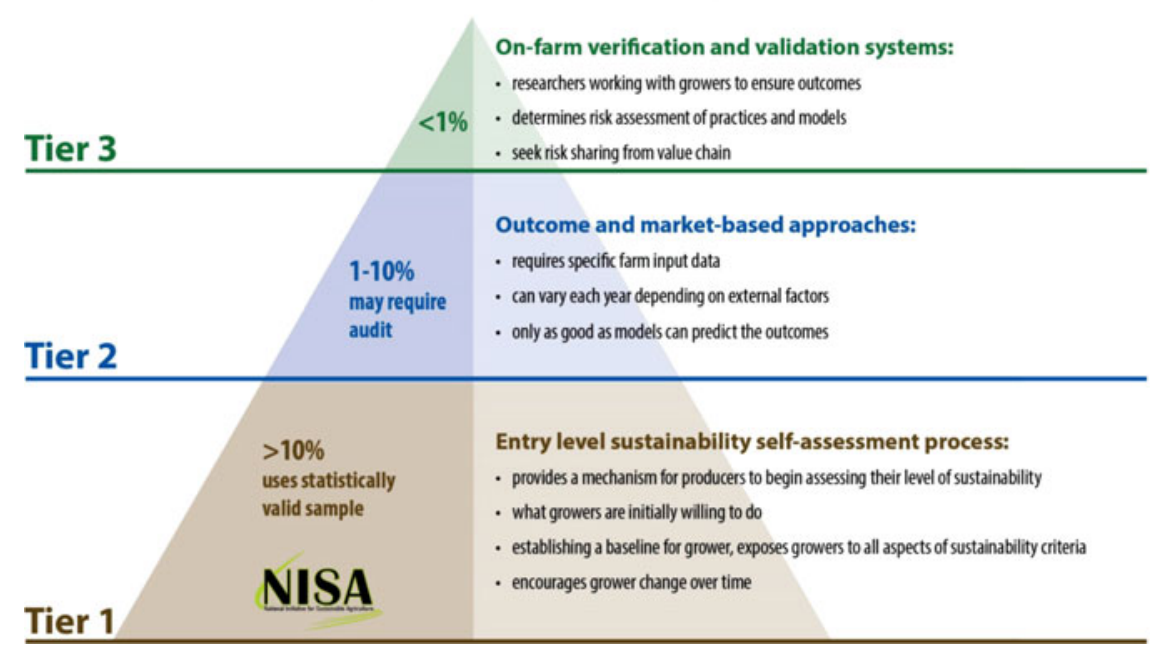

Figure 1. Description of a tiered-approach to agricultural sustainability assessment and the percentage of growers participating in each tier.

Research and Education Program, 2015). For example, the 1977 Farm Bill officially defined sustainable agriculture as

" [A]n integrated system of plant and animal production practices having a site-specific application that will over the longterm-(A) satisfy human food and fiber needs; (B) enhance environmental quality and the natural resource base upon which the agriculture economy depends; (C) make the most efficient use of nonrenewable resources and on-farm resources and integrate, where appropriate, natural biological cycles and controls; (D) sustain the economic viability of farm operations; and (E) enhance the quality of life for farmers and society as a whole." (National Agricultural Research, Extension, and Teaching Policy Act of 1977 (7 U.S.C. 3103 (19)). 1977. Available at http://www.gpo.gov/fdsys/pkg/ USCODE-2011-title7/html/USCODE-2011-title7-chap64.htm

This definition was reaffirmed in the 1990 Farm Bill (Food, Agriculture, Conservation, and Trade Act of 1990, Public Law 101-624. Title XVI, Subtitle A, Section 1603. Available at http://thomas.loc.gov/cgi-bin/ query/F?c101:4:./temp/ c101jiTXK1:e1108836) and the National Research Council adopted a similar definition in 2010 (National Research Council, 2010).

Consumers commonly express willingness to pay premiums for products with sustainability attributes (Blend and van Ravenswaay, 1999; Nimon and Beghin, 1999; Teisl, Roe and Levy, 1999; Onozaka and McFadden, 2011; Dong, Mitchell and Colquhoun, 2015), which reflects their concern about society and the environment. In order to capture potential price premiums or maintain market access, supply chain partners push for documentation of the current status of and improvements in agricultural sustainability and moreover for sustainability assessments so that they can make claims to differentiate their products from others (Lendle and Schaus, 2010;
Murphy et al., 2014; Gibbs et al., 2015). Documenting input use and environmental outcomes at the farm level is often time consuming, seems overly intrusive to farmers and, consequently, is difficult and expensive to collect (Pennings et al., 2002). A more practical approach to assess on-farm sustainability should engage a large number of farmers in the process by using a practicebased, self-assessment that is easy to complete, not intrusive or cost prohibitive, and yet able to establish an accurate baseline of adopted practices. Such an approach can serve as an entry-point into a multi-tiered agricultural sustainability assessment as described in Figure 1.

A Tier 1, entry-level assessment of practices (Fig. 1) is a foundational component of a multi-tiered approach to measuring sustainability that can then be linked with higher-tiered, outcome-based sustainability programs. It is a low-cost way to introduce sustainability to a large number of farmers and help them understand that sustainability is consistent with many of their own goals. Furthermore, it can ensure market access (Lendle and Schaus, 2010; Gibbs et al., 2015) or serve as a way to recruit farmers interested in more intensive approaches to pursuing sustainability.

Tier 2 agricultural sustainability programs pursue potential market premiums, but require more intensive data on input use and practices to provide accurate estimates of sustainability outcomes that reflect regional variability (Fig. 1). Such programs would collect relevant information from a smaller segment of farmers, but could use practice data from Tier 1 participants. Tier 3 programs represent a validation phase of assessing sustainability that builds a scientific foundation by experimentally measuring the linkages between practices and sustainability outcomes on a small number of farms. Because these research or show-case farms would be 
expensive to run, as they would collect and analyze a substantial amount of data, they would be few in number (Fig. 1).

In this context, our approach centers on the Tier 1 program. It develops a comprehensive set of good farming practices for Midwestern soybean farmers as a practical and concrete definition of agricultural sustainability for these farmers. Science-based practices are chosen that broadly address the three aspects of sustainability (environmental, economic and social) and are consistent with more official definitions of sustainability (e.g., those defined in the 1977 and 1990 Farm Bill; and by National Research Council, 2010). After using this set of practices as a self-assessment survey to collect farmer adoption data, we apply a process to calculate an index number for each farmer; a composite indicator that measures practice adoption intensity as a sustainability metric. Such a composite indicator informs individual farmers how their sustainability practices and/or outcomes compare with their peers and identifies specific practices or outcomes to improve their sustainability performance. In our interactions with farmers who completed the assessment, they especially like the scorebased peer comparisons and specific feedback regarding practices they can adopt to improve. At the aggregate level, the distribution properties of the composite indicator describe how the farm population is performing as a whole and over time, which can be useful for developing and evaluating policies and programs to improve wholefarm sustainability.

The objectives of this study are first to develop and implement an entry-level sustainability self-assessment tool to document on-farm practices in Midwestern soybean production systems. We then use these data to: (1) evaluate a composite sustainability scoring system for Midwestern soybean farmers; (2) identify the practices that drive Midwestern soybean on-farm sustainability; and (3) illustrate how increased farmer adoption of these key practices affects individual farmer sustainability scores and the distribution of all sustainability scores.

\section{Materials and Methods}

\section{Assessment tool development}

Some key factors that guided development of the sustainability self-assessment included farmer engagement, a focus on science-based practices, cost-effective use of farmer time and anonymity. An important part of getting farmers to engage with the assessment process was to involve them directly in the development of the survey assessment, so that they became active participants in defining agricultural sustainability for themselves. Not only is this consistent with the social component of sustainability, but it also helps improve survey design and increase participation (Dillman et al., 1993). Farmers generally support a practice-based approach to agricultural sustainability that is consistent with most other agricultural programs, but the practices must be science-based with demonstrated sustainability benefits. Thus, the researchers, farmers and agricultural professionals involved in developing the assessment, focused on good management practices with positive outcomes that enhanced sustainability as documented in the scientific literature. Anonymity was important, as many farmers were concerned that the information would be used against them by government agencies for regulatory purposes, in the media by activists, or by companies to extract gain (Pennings et al., 2002; Bunge, 2014). Finally, the farmers involved emphasized that the assessment could not be time consuming or ask for information that required looking for information in farm records (Pennings et al., 2002), and so an entry-level assessment was developed as a low-cost approach to achieve wider participation (Fig. 1).

University research and Extension state specialists first developed a list of whole-farm and soybean-specific practices, guided by the expected outcomes for sustainable cropping practices described by the National Initiative for Sustainable Agriculture (NISA) (NISA, 2014a, b). All of the practices were drawn from accepted 'best management practices' in cash grain and soybean production guides and validated in peer-reviewed literature. These best management practices are promoted by Extension faculty and industry professionals annually in the Midwest, and are published annually in Extension recommendations (Schulte et al., 2005; Conley et al., 2011a, b; Laboski and Peters, 2012; Cullen et al., 2014) and regularly in refereed journal articles describing optimal crop and soybean management (Alexander et al., 2007; Conley et al., 2007, 2011a, b; Conley and Santini, 2007; Johnson et al., 2007; Hanna et al., 2008; Robinson et al., 2009; Davis and Conley, 2011; Furseth et al., 2011, 2012; Esker and Conley, 2012; Rowntree et al., 2013, 2014; Rincker et al., 2014; Marburger et al., 2014).

These practices were converted into questions for a sustainability self-assessment survey, and then this survey was emailed to farmer leaders in state and national soybean associations around the US Midwest for feedback. Farmers were invited to provide specific feedback on the clarity and appropriateness of each question, whether the practice made sense as a 'good' practice for Midwestern soybean farmers, and to suggest additional practices that should be included. Next, a focus group was conducted in conjunction with a conference that most of these farmers attended. At this focus group, farmer leaders who were chosen with the help of state soybean associations, the North Central Soybean Research Program, and the United Soybean Board, provided specific comments and feedback, and as a result, several questions were changed, some dropped and new ones added. After that, a revised version of the sustainability self-assessment survey was sent around again for additional comments from farmers, researchers and industry leaders. 
Following feedback from the focus group farmers and academic research (Pennings et al., 2002) on the types of sustainability questions that farmers would complete, the questions were constructed, so that a farmer would not have to consult records or give detailed information about input use. Also, most of the questions required 'yes' or 'no' answers, or choosing options from a list, so that the entire survey took less than an hour to complete.

Many practices do not pertain to a specific crop, but to many crops or to the farm operation in general, while others are specific to soybeans. As a result, the assessment included a soybean-specific section and a whole-farm section and was administered separately. This choice proved appropriate, since fewer farmers were willing to complete the substantially longer whole-farm assessment.

Based on farmer feedback, most farmers would not be willing to voluntarily share detailed information on their use of specific inputs, costs and profitability. As a result, some questions focused on maintenance of written plans or long-term records and attendance at farmer educational meetings and use of information. These practices are used as indicators of farmers who carefully planned input use, understood general agronomic principles and were aware of non-target and off-site impacts of their decisions, under the assumption that this planning and awareness led to appropriate use of inputs. Similarly, rather than asking for estimated carbon footprints, profitability, or other key outcomes, the self-assessment only asked if they had completed such estimates, under the assumption that these farmers would use this information appropriately. The final self-assessment contained questions about use of more than 200 practices and is available online (National Sustainable Soybean Initiative, 2014; National Initiative for Sustainable Agriculture, 2014a, b). Because the full set of questions and practices is quite long, only a short overview of each category is provided here. A complete list of the specific questions and practices is available (Dong et al., 2012).

Tables 1 and 2 list the main assessment categories along with example questions for the whole-farm section and the soybean-specific assessment, respectively. The wholefarm section contains questions on farming practices in eleven categories: farm soil and nutrient management, crop scouting, farm pest management, resistance management, chemical and worker safety, ecosystem restoration, farm production and management, farm learning and research, farm sustainability and community, farm economics and farm energy management. The soybean-specific assessment contains questions on farming practices in four categories: soybean production and management, weed management, insect management and disease management.

For the whole-farm assessment, farm soil and nutrient management focused on practices to manage wind and water erosion, such as conservation tillage, wind breaks, cover crops and filter strips, having nutrient management plans and following University nutrient use guidelines.
Controlling soil erosion to maintain long-term land productivity and appropriate use of crop nutrients to reduce off-site losses of nutrients are keystones of agricultural sustainability (Tillman et al., 2002; Montgomery, 2007). Crop scouting focused on scouting methods (i.e., formal versus informal) and the purposes of the scouting (i.e., to reduce pesticide use, or to monitor efficacy and known 'hot spots'), as well as the quality and long-term maintenance of records, and use of advanced scouting practices such as remote sensing. Scouting is a cornerstone of integrated pest management (IPM), a key part of agricultural sustainability (Tillman et al., 2002; Castle and Naranjo, 2009). Farm pest management was a long check list of best management practices for weed, insect and disease management promoted by Extension faculty and industry professionals, such as controlling weed escapes, preserving natural enemies and rotating crops to manage soil-borne diseases (Cullen et al., 2014). Resistance management to maintain the effectiveness of pest control focused not only on rotating modes of action, but also on planning, record keeping, and efficacy monitoring, as well as use of cultural control methods. Resistance management and IPM are important, not only for reducing excessive and unnecessary pesticide use, but also for maintaining the effectiveness of pest management practices besides pesticides (Tillman et al., 2002).

Chemical and worker safety focused on equipment maintenance, worker certification and safety training, use of protective clothing and equipment, the adequacy of on-farm storage facilities and practices to mitigate drift, non-target and other off-site impacts. Human safety is an important part of the social component of sustainability, often emphasized in corporate sustainability assessment systems (Labuschagne et al., 2005).

Ecosystem restoration not only included specific practices such as planting or protecting native ecosystems and pollinator habitat, but also activities such as meeting with ecologists, having a written restoration or pollinator protection plan, attending educational meetings, and knowing the natural ecosystems on the land they manage. Ecosystem restoration is important for enhancing biodiversity to increase ecosystem services (Tillman et al., 1996, 2002).

Farm production management examined crop rotations, calibration and maintenance of field equipment and limiting soil compaction. These are commonly recommended practices to maintain soil productivity and prevent wasted or inefficient field operations (Schulte et al., 2005; Conley et al., 2011a, b). Farm learning and research focused on continuing education activities (educational meetings, field days and newsletters), conducting on-farm research and tracking practice efficiency using long-term field records and precision agriculture data. Continuing education activities and maintaining written plans and records indicate farmers, who carefully plan input use, understand general agronomic 
Table 1. Categories and example questions for the whole-farm sustainability assessment.

\begin{tabular}{ll}
\hline Category & Example practices and response options
\end{tabular}

Farm soil and nutrient management (eight practices)

Crop scouting (15 practices)

Farm pest management (including weeds, insects, and diseases) (25 practices)

Resistance management (17 practices)

Pesticide and fertilizer handling and worker safety (9 practices)

Ecosystem restoration (9 practices)

Farm production and management (8 practices)
- Do you sample soil for nutrients in accordance with University guidelines regarding frequency and number of samples? (Yes or No)

- Do you have an annually updated nutrient management plan that follows University recommended application guidelines? (Yes or No)

- Are effective winter covers planted? (Yes or $\mathrm{No}$ )

Why do you scout? (Check all that apply)

- To determine when pest levels in a field reach or exceed thresholds

- To reduce pesticide use and so minimize environmental impacts

- To check on the effectiveness of a pest control measure used

- In response to a local or recent pest report heard or read about

- To monitor areas of fields where pests were a known problem

Which of the following practices did you use on your farm for insect management? (Check all that apply) [select options shown]

- Managed cropping system locations to avoid pest concerns from previous to current year's crop

- Used augmentative biological control with beneficial insects released in the area either prior to or during the growing season

- Managed or enhanced the habitat in or around the field to encourage or conserve beneficial insect populations

- Do you rotate modes of action to limit resistance selection? (Yes or $\mathrm{No}$ )

- Do you choose pesticide rates within the labeled range to be sufficient to prevent pest reproduction or resistance selection? (Yes or No)

- Do you monitor and keep records of the performance of pesticides with high risk for resistance for individual fields? ( Yes or $\mathrm{No}$ )

- Do you monitor and keep records for individual fields of the performance of pesticides with high risk for resistance? (Yes or No)

- Was your spray equipment (or the custom applicators' equipment) calibrated before this crop season (e.g., each nozzle with same flow and coverage rate)? (Check only one)

- 4 or more times per year

- 3 times per year

- 2 times per year

- 1 time per year

- Not at all

- Is all personal protection clothing and equipment used during pesticide applications appropriate for worker safety? (Yes or $\mathrm{No}$ )

- Do you know what natural plant and ecosystem community types and biodiversity you have on your land?

- Yes, please specify source

○ No

- Did you implement any practice to enhance conservation of native wildlife or general biodiversity in and/or around your farm and/or privately owned lands? (Check all that apply) [select options shown]

- Planted diverse native vegetation for pollinators (e.g., prairie seed mixes in landscapes that were historically grassland

- Planted native vegetation in buffer zones

- Enrolled in conservation incentives

- Is all planting equipment calibrated to ensure accurate planting rates? (Yes or $\mathrm{No}$ )

- Is all planting, harvest, tillage and field equipment cleaned and sanitized at least twice per year? (Yes or No)

- Do you use practices to limit compaction on the farm? (Check all that apply)

- Correct tire inflation and/or tracks (reduce psi as much as practical)

- Control traffic patterns

- Add a deep tap rooted crop (e.g., alfalfa) 
Table 1. (Cont.)

Category $\quad$ Example practices and response options

Farm learning and research (10 practices)

Farm sustainability and community (12 practices)

Farm economics (21 practices)

Farm energy management (11 practices)
- In the past year, did you or your farm manager attend any University or Extension-sponsored field days or educational meetings regarding farm, crop and ecosystem management?

- Yes, list specific meetings

- No

- Have you conducted on-farm research (replicated) in collaboration with University, Extension or similar entities? (Check all that apply)

- Yes, with University specialists

- Yes, with private industry specialists

- No

- I have a sustainability mission statement for my operation that contains information on my sustainable farming/operations philosophy. This information is presented to all employees. (Yes or $\mathrm{No}$ )

- I have implemented a recycling program for my operation. (Yes or $\mathrm{No}$ )

- I buy my production inputs from a local (e.g., state) source. (Yes or No)

- Each year I track revenues and net returns for my major crops. (Check only one) - Yes, by field and crop

- Yes, by crop

- No

- I have a recent balance sheet and income statement for my farm on file. (Yes or No)

- I meet with a financial or business advisor to review my farm's financial status and profitability. (Check only one)

- Yes, 3 or more times per year

- Yes, 1-2 times per year

- No

- I have conducted an energy audit on my farm. (Yes or $\mathrm{No}$ )

- I have improved fuel efficiency over time by changing vehicle size, fuel efficiency, load, scale or using other methods

- Yes, please specify

- No

- I have used tools to reduce energy use (e.g., efficient pumps, variable frequency drive fans and new mechanisms)? (Yes or No) principles and are aware of non-target and off-site impacts of their decisions, which contribute to appropriate use of inputs.

Farm sustainability and community included conducting sustainability assessments, use of on-farm recycling and involvement in a range of community activities, both agriculturally focused and more general. Recycling and conducting sustainability assessments demonstrate farms that have already been pursing sustainability, while community involvement shows a farmer's commitment to enhancing the local community as part of the social component of sustainability.

Farm economics focused on tracking costs and returns, use of marketing plans and strategies, as well as buying insurance and having disaster plans. These practices indicate farms that take the time to understand their farm and field level economics and so are more likely to achieve a higher level of economic sustainability, while insurance and disaster plans improve a farm's capacity to economically survive bad events (Nivens et al., 2002). Farm energy management focused on use of practices to improve energy efficiency, conducting energy audits, and use of renewable energy, and other practices to reduce net greenhouse gas emissions.

For the soybean-specific assessment, soybean production and management focused on crop rotation, soybean planting and establishment practices, practices to reduce soil erosion and improve soybean nutrient management, and key soybean harvest and storage practices to prevent storage losses. Soybean weed, insect and disease management used long check lists of best management practices promoted by Extension faculty and industry professionals, such as scouting to make control decisions, monitoring to determine control efficacy and to identify escapes, rotating modes of action and use of a variety of cultural control practices. These commonly recommended management 
Table 2. Categories and example questions for the soybean-specific sustainability assessment.

Category Example practices and response options

Soybean production and management (39 practices)

Soybean weed management $(13$ practices)

Soybean insect management (11 practices)

Soybean disease management (seven practices)
- Which of the following practices did you use to maintain soil quality and quantity? (Check all that apply)

- Managed pH levels to encourage optimal productivity of soybeans (target $\mathrm{pH}$ levels at least 6.2)

- Used tillage and management practices which maintain residues on soil surface

- Fields were worked perpendicular to dominant slopes of greater than $4 \%$ (e.g., contour strips)

- Soybeans were planted no-till

- Which of the following practices did you use during this growing season? (Check all that apply) [select options shown]

- Reviewed previous scouting records and planned a weed management strategy focused on key weed challenges

- Reviewed previous herbicide records to ensure that herbicide carryover from a previous crop is not a concern

- Rotated herbicide mode-of-action and/or utilized tank-mixtures to slow the development of herbicide resistance in accordance with manufacture and Extension recommendations

- Monitored and managed field edges to limit weed seed migration into fields

- Which of the following practices did you use to manage insects? (Check all that apply) [select options shown]

- Rotated classes of insecticides specifically to avoid the emergence of insect resistance

- Used thresholds for soybean aphid (when $80 \%$ of the field averages 250 aphids per plant and population is increasing)

- Biocontrol methods (beneficial insects, augmentative releases, or biological products) were used for insect control

- Scouted soybean for insect pests at least weekly in a systematic pattern throughout the field and over the growing season

- Culturally managed a soybean insect pest (e.g., wireworm, white grubs) with the crop planted prior to soybean in this field

- Which of the following practices did you use to control diseases? (Check all that apply) [select options shown]

- Sampled for soybean cyst nematode populations (one sample per each 10 acres)

- Planted a disease tolerant variety

- Scouted soybean for disease weekly in a systematic pattern throughout the growing season

- Used foliar fungicides only when risk to plant for disease infection was high practices provide a range of benefits, such as preventing wasted or inefficient use of inputs or field operations and maintaining the efficacy of pest control (Schulte et al., 2005; Conley et al., 2011a, b; Laboski and Peters, 2012; Cullen et al., 2014).

\section{Data collection and summary}

Farmer self-assessment response data were collected in two ways - using paper copies at extension meetings in Wisconsin and online. University of Wisconsin Extension regularly holds winter education meetings on soybean production around the state. At meetings in January-February, 2013, attendees were given paper copies of the self-assessments and time to complete them during the meeting. The meeting agenda included an explanation of what the self-assessment was, why they were being asked to complete it, assurances that it was voluntary and that their data would remain anonymous, and that the project was funded by the United Soybean Board (a grower funded organization) (Conley, 2013). Online versions of the self-assessments (National Sustainable Soybean Initiative, 2014a, b; National Initiative for Sustainable Agriculture, 2014) were publicized by the state soybean associations. The Illinois Soybean Association offered incentives for Illinois soybean growers to complete the assessments-US\$25 each for the whole-farm and soybean-specific assessments.

As a result of the data collection process, most of the responses were from Illinois and Wisconsin farmers, but 
because the assessment tool was online and mentioned at regional and national meetings, some of the farms are from other states. The final data used for this analysis included 410 completed soybean-specific assessments and 80 whole-farm assessments. Of the 410 completed soybean-specific assessments, 296 were from Illinois, 79 from Wisconsin, 16 from Minnesota, four from Iowa, three from Missouri, one each from Alabama, Indiana, Kansas, North Dakota and Pennsylvania, and seven unknown. Similarly, of the 80 completed whole-farm assessments, 33 were from Wisconsin, 31 from Illinois, nine from Minnesota, one each from California, Iowa, Kansas, Kentucky, North Dakota, Virginia and one unknown.

Given these data collection methods, these responses are a convenience sample, but generally representative of commercial cash-grain farmers. The average size of the farms for the analysis was 531 ha for the soybean-specific assessments and 603 ha for the whole-farm assessment. An average of 250 ha of soybeans was planted by farms in soybean-specific assessments. In 2012, 77\% of the US soybean planted area was on farms planting at least 100 ha of soybeans, with an average of 272 ha of soybeans per farm (USDA, 2014), which is roughly consistent with the average for the soybean-specific assessments. In total, the soybean-specific assessments represent information from about 210,000 ha of farm land and more than 102,000 ha of soybeans, while the whole-farm assessments capture information from about 48,000 ha of land.

Summaries of responses for the all the practices is beyond the scope of this paper. A summary of assessment highlights prepared for a general audience is available (Knuteson et al., 2014), and so here we highlight responses to some practices from each category. Of the respondents, $92 \%$ reported following recommended nutrient management guidelines and 91\% reported using reduced and no-till practices, but only $66 \%$ had a soil and water conservation plan. In addition, $88 \%$ used scouting practices and $85 \%$ used threshold for pest management decisions, but only $38 \%$ maintained scouting records for more than 2 years. However, 95\% reported using cultural practices for insect, weed and disease management, yet only $48 \%$ reported managing pests in previous years to avoid insect pests in the current crop. In terms of resistance management, $80 \%$ reported rotating modes of action and $75 \%$ used diverse modes of action in rotational crops. Among respondents, $84 \%$ used technologies to minimize drift and $83 \%$ calibrated spray equipment to limit over application.

Ecosystem restoration practices were not highly adopted-34\% were enrolled in conservation incentive programs, $23 \%$ attended ecological training sessions and $28 \%$ had developed an ecological management plan for their land, yet $73 \%$ used practices to conserve native wildlife. Of the respondents, $90 \%$ reported having a rotation at least 2 years, but only $42 \%$ reported cleaning and sanitizing their equipment at least twice per year. For learning and research, $78 \%$ attended informational sessions, $60 \%$ attended University-sponsored field days, and $68 \%$ conducted on-farm research with science-based partners. Of the respondents, $82 \%$ bought inputs locally, with $66 \%$ involved in community service organizations and $33 \%$ serving in local community leadership positions.

For farm economics, $82 \%$ completed a cost of production analysis by crop, but only $53 \%$ had a marketing plan and $47 \%$ had a farm succession plan, with $85 \%$ having property insurance and $79 \%$ having business liability insurance. Finally, 90\% used practices to limit energy use to improve efficiency, while $53 \%$ had improved fuel efficiency of farm vehicles and equipment over time.

\section{Methodology for data analysis}

The soybean sustainability assessment includes a large number of discrete variables measuring practice adoption. In addition, these variables are highly correlated, since practices tend to be adopted together (e.g., scouting for insects, for weeds and for diseases or use of soil nutrient tests and of plant tissue tests to guide nutrient applications). Given the discrete and correlated nature of the data, we use the method developed by Dong et al. (2015) that combines principal component analysis (PCA) with data envelopment analysis (DEA) to construct a composite indicator.

PCA is a well-known multivariate analysis technique introduced and developed in the early 20th century (Pearson, 1901; Hotelling, 1933; Jolliffe, 2002). PCA is used to reduce a data set having a large number of interrelated variables into a smaller data set of uncorrelated variables, called principal components, that retains as much of the variation in the original data as possible (Jolliffe, 2002). Common-weight DEA has been used to construct composite indicators (Despotis, 2005; Hatefi and Torabi, 2010). However, the method of Dong et al. (2015) first uses non-negative polychoric PCA to process the data in order to address weaknesses of DEA. DEA is a widely used linear programming process. It allows benchmarking the performance of individual decision making units against a frontier based on the observed behavior and/or outcomes of other decision-making units (Cooper et al., 2007). The large dimension of the data set and correlations among variables reduce the discrimination power of DEA and introduces bias (Nunamaker, 1985; Dyson et al., 2001). The non-negative polychoric PCA reduces the number of variables, removes correlation, transforms discrete variables to continuous principal components, and ensures that all principal component elements are non-negative. The resulting principal components are suitable for the common-weight DEA, which further increases the discrimination power of DEA (Despotis, 2002).

The specific mathematics of the non-negative polychoric PCA and common-weight DEA process are briefly summarized here. More details about the method can be 
found in Dong et al. (2015). First, the PCA with a nonnegativity constraint on individual elements of the principal vectors is conducted on the polychoric correlations of practice variables. In the second step, common-weight DEA is conducted using the principal components obtained from PCA. The common-weight DEA approach finds the set of common weights by solving a mathematical programming model that minimizes the weighted sum of the average deviation of the common-weight DEA scores over all farms and the maximum deviation of the common-weight DEA scores from the basic DEA score among all farms. In contrast to basic DEA which chooses a farm-specific weight for each principal component, common-weight DEA chooses a single weight for each principal component that is equal for all farms, which improves the discriminating power of DEA (Despotis, 2002, 2005).

The method utilizing PCA for common-weight DEA generates a weight for each practice and a composite sustainability score for each farm that can be used to evaluate two factors, the importance of each practice in sustainability assessment and the level of each farm's sustainability level.

\section{Alternative scenario}

The weight for each practice in sustainability assessment indicates the relative contribution of the practice to the final sustainability scores. Non-adoption of the practices with the highest weights is a major reason some farms have low scores, and as such, these practices indicate to producer organizations, policy makers and other stakeholders sustainability practices to target for higher adoption. To illustrate this advantage, the analysis here first identifies the ten practices with the highest weights for the soybean-specific and for the whole-farm assessments. Next, an alternative scenario is developed in which the farms in the lowest 10th percentile of scores adopt these ten practices, and then the PCA-DEA analysis is repeated for both data sets with this alternative practice adoption profile.

Comparing results for this alternative scenario to the original results indicates how increased practice adoption by the lowest performing farms affects not only the scores for all farms, but also the distribution of scores for the sample population. This alternative scenario illustrates how a producer group could use this assessment process to identify practices to target for adoption, and then how analysis results would change if the group were successful in encouraging their lowest performing members to adopt these targeted practices.

\section{Results and Discussion}

Non-negative polychoric PCA and common-weight DEA were separately conducted on the 70 practice variables in
Table 3. Statistical description of soybean-specific and wholefarm sustainability scores from farmer self-assessment conducted in 2012/13 in the US Midwest. Scores potentially range from 0 for the lowest level of sustainable practice adoption to 1 for the greatest level of sustainable practice adoption.

\begin{tabular}{lcc}
\hline Statistic & $\begin{array}{l}\text { Soybean-specific } \\
\text { assessment }\end{array}$ & $\begin{array}{l}\text { Whole-farm } \\
\text { assessment }\end{array}$ \\
\hline Average & 0.846 & 0.842 \\
Minimum & 0.515 & 0.624 \\
Maximum & 1.000 & 1.000 \\
$25 \%$ quantile & 0.795 & 0.737 \\
$50 \%$ quantile & 0.866 & 0.862 \\
$75 \%$ quantile & 0.917 & 0.959 \\
Standard & 0.099 & 0.129 \\
deviation & & \\
\hline
\end{tabular}

the soybean-specific sustainability assessment metrics and on the 145 practice variables in the whole-farm sustainability assessment. This analysis gave each farm a sustainability score on each assessment. The average score was 0.846 , with a standard deviation of 0.099 and range from 0.515 to 1.000 for the soybean-specific data (Table 3). Similarly, for the whole-farm data, the average score was 0.842 , the standard deviation was 0.129 , and the range was from 0.624 to 1.000 . Though the average scores are essentially equal for the two assessments, the standard deviations and ranges differ.

To show how the distributions differ, Figure 2 depicts histograms of these scores separately for each data set. The histogram for the 410 soybean-specific scores shows a fairly smooth distribution with a mode just above the mean and a long lower tail that diminishes, while the histogram for the 80 whole-farm scores shows a large peak near 1.0 with over $25 \%$ of the farms scoring over 0.95 , then a relatively flat tail stretching to the observed minimum. Some of the relative smoothness of the histogram for the soybean-specific scores is likely due to having 410 observations, versus only 80 for the wholefarm scores.

In terms of interpretation, the highest scores (1.000) are for those farms adopting the most practices on the assessments and all other farms are scored relative to these high adopters. The results for both the whole-farm and the soybean-specific assessments show that a substantial portion of farms have relatively similar levels of practice adoption, as most scores exceed 0.85 (Table 3). These farms could adopt a few more sustainable practices to further increase their scores. More importantly, however, a lower tail exists for both assessments, indicating substantial potential exists for these relatively low-performing farms to increase their adoption of practices. Because these low-scoring farms have the greatest potential for improvement, we illustrate the ability of this analysis method to document sustainability improvements by assuming the lowest performing farms in the lower tails 

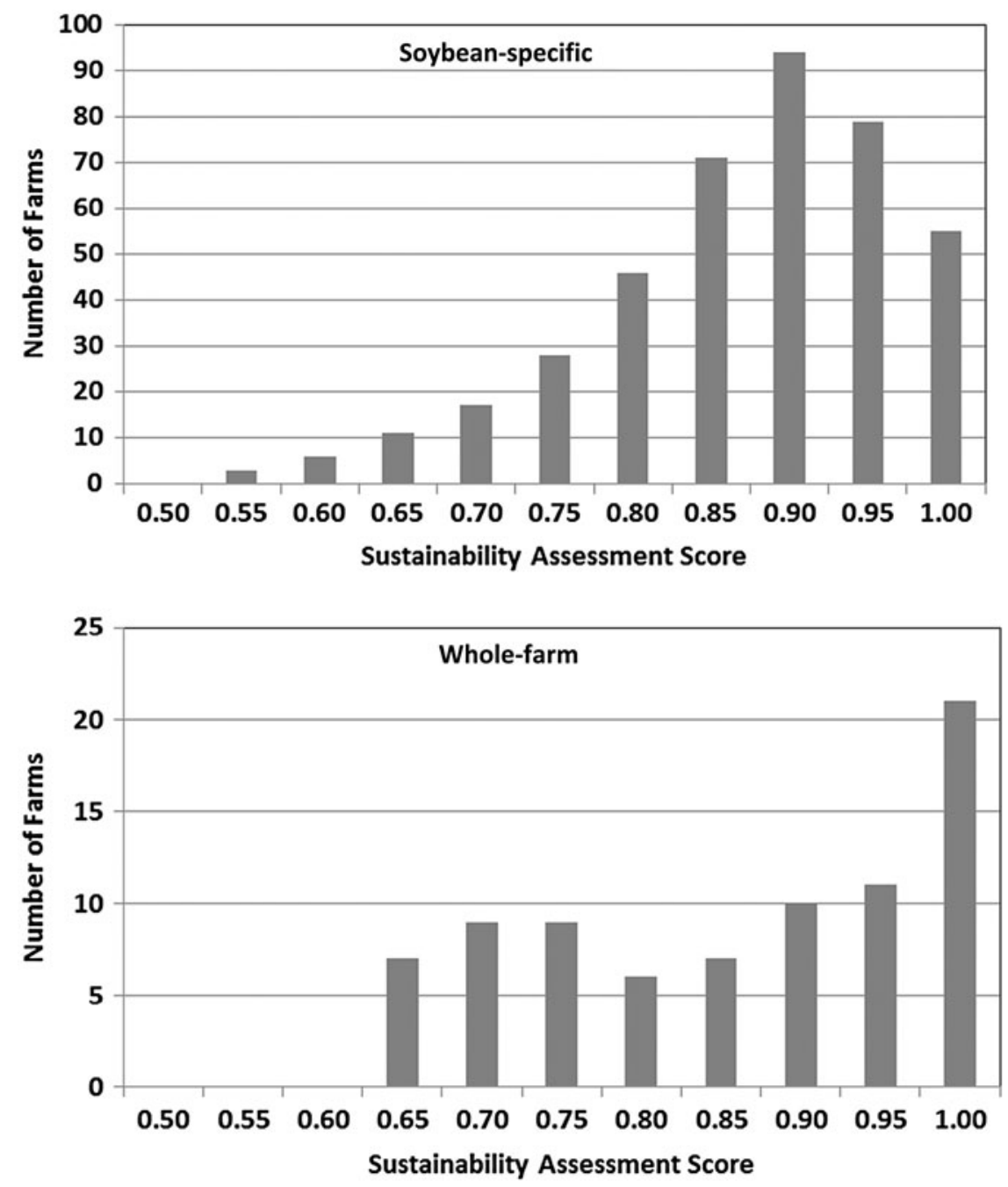

Figure 2. Histogram of farm sustainability scores from analysis of the whole-farm and soybean-specific assessment data.

adopt more sustainable practices, and then repeating the sustainability analysis for both assessments.

An advantage of the PCA-DEA process used here is that it gives each practice in the survey a weight for its contribution to individual farm sustainability scores. Tables 4 and 5 respectively report the ten practices with the highest weights for the soybean-specific and the whole-farm sustainability assessments. For farms with high sustainability scores, adoption of these practices substantially contributes to their high scores, while farms with low scores rarely adopt these practices and could increase their scores by adopting these highly weighted sustainability practices.

For the soybean-specific assessment (Table 4), six of the practices identified as important involve management practices associated with integrated pest and disease management, including different scouting activities and practices for judicious and appropriate use of pesticides. These practices are important for sustainability, as poorly managed pests can greatly reduce crop yields, but excessive or wasteful pesticide use generates unneeded human and environmental health impacts, while cultural control options can reduce the need for pesticides (Tillman et al., 2002; Cullen et al., 2014). Crop rotation practices were also identified as key drivers of sustainability, with farmers using longer and/or more diversified rotations given higher scores. Crop rotation has a variety of benefits, from increasing soil productivity to improved pest control (Laboski and Peters, 2012; Cullen et al., 2014). The final two practices, which were given the greatest weights, focus on planting and post-harvest activities. No-till planting has several advantages, such as lower energy use, less erosion and improved soil structure, but requires enhanced management to reduce yield loss, such as adjusting the planter to soil conditions to ensure good stand establishment (Conley et al., 2011a, b; Pittelkow et al., 2015). Grain dryers that recirculate air or stir grain should be avoided as they increase the risk for grain damage and loss during storage (Iowa State University Extension, 2008).

In the whole-farm assessment, practices associated with IPM, especially scouting, were again important. In 
Table 4. Top ten practices driving sustainability scores for the soybean-specific assessment (the ten practices in the soybean-specific assessment with the greatest weights).

Avoided grain dryers that re-circulate air

Consulted seed supplier to determine growing condition and/or disease concerns when choosing

Table 5. Top ten practices driving sustainability scores for the whole-farm assessment (the ten practices in the whole-farm assessment with the greatest weights).

Maintained hunting or tourist lands to be economically diverse

addition, practices to enhance economic diversity were identified as key sustainability drivers, including longer crop rotations for a more diverse crop mix, livestock production and even maintaining hunting/tourist uses of land. Maintaining diverse sources of livelihood is recognized as important for economic sustainability (Robinson et al., 2015). Practices to keep management current were also important, such as receiving industry newsletters and conducting on-farm research with university specialists. Finally, the analysis identified efforts to reduce wind erosion as important for sustainability, a type of erosion usually not addressed in the Midwest where sheet and rill erosion are more of a problem (USDA-NRCS, 2010).

Regarding the other practices on the assessments, many soybean farmers had already adopted crop rotation and practices that conserve soil, including reduced and/or no-till cultivation and using contour strips to limit soil loss. In addition, many already used cultural control practices for insect, disease and weed management, and practices that limit energy use. Completing a cost of production analysis was also very common among soybean farmers. However, the analysis gave these practices less weight since so many farmers had already adopted them. The final weight for each practice is determined by the PCA weight, the DEA weight and the standard deviation of practice adoption among farmers (Dong et al., 2015). Though many practices such as crop rotation, reduced tillage and use of cultural control for pest management are clearly also important for sustainability, the analysis gives less weight to them because most farmers have already adopted them. Practices that most farmers already use have little variation among farmers and do not help differentiate farmers from one another, and so have lower weights.

To illustrate how changing the practice adoption profile of the farmer population impacts the sustainability scores, a hypothetical scenario was developed in which farms at the lowest 10th percentile were assumed to adopt the ten practices listed in Table 4 for the soybean-specific assessment and ten in Table 5 for the whole-farm assessment, and then the analysis repeated. Comparing results to the original scores indicates the effects of a targeted policy focused on improving sustainability of farms 

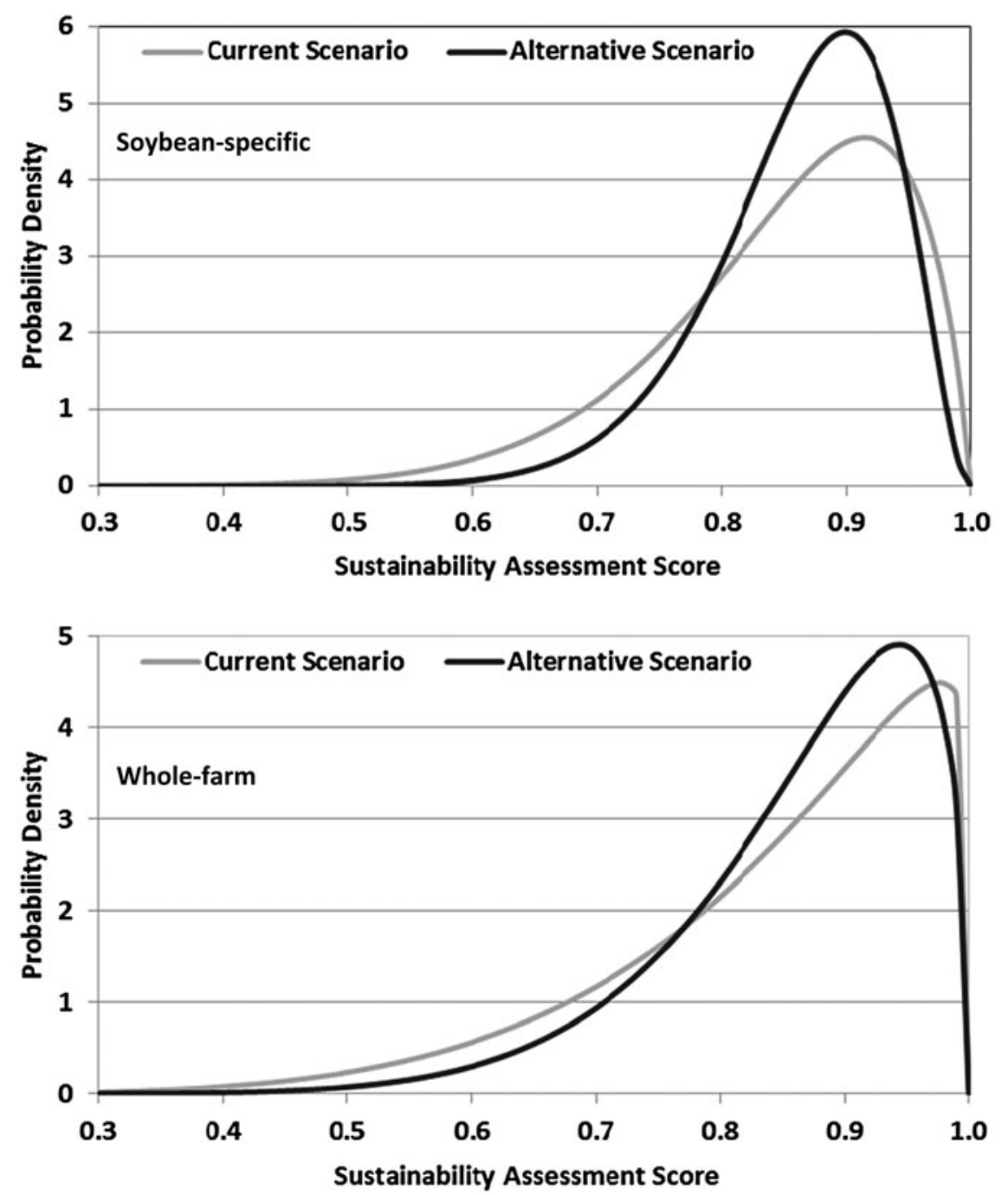

Figure 3. Estimated beta probability density functions for the distribution of sustainability assessment scores for the soybean-specific and whole-farm assessments for the current and alternative scenarios.

ranked at the bottom by the original assessment. Different farms and different practices could be selected for a hypothetical scenario depending on proposed policies and goals.

Results for the original and hypothetical scenarios are first compared by examining the shift in the distribution of scores for the farm population. In terms of population statistics, the sample average score for the hypothetical scenario relative to the original analysis increased from 0.846 to 0.862 for the soybean-specific assessment, and from 0.842 to 0.862 for the whole-farm assessment, about a $2 \%$ increase in both cases. Similarly, the minimum score increased from 0.515 to 0.647 for the soybean-specific assessment, and from 0.624 to 0.685 for the whole-farm assessment, which decreased the standard deviation, from 0.099 to 0.072 for the soybean-specific assessment and from 0.129 to 0.101 for the whole-farm assessment. The changes in the mean of the lowest 10th percentile farms are much larger, which increased from
0.635 to 0.819 for the soybean-specific assessment and from 0.634 to 0.920 for the whole-farm assessment.

To make shifts in score distributions easier to discern, empirical histograms are converted to parametric probability distributions. Specifically, a beta probability density function is assumed, since it is a flexible distribution ranging between 0 and 1 . The observed sample mean and standard deviation of the scores are used to calculate the implied shape parameters of the beta density with a range of $0-1$ using the equations reported in Evans et al. (2000). Figure 3 plots the probability density functions for the scores for the original and the hypothetical scenarios for both the soybean-specific and the wholefarm assessments. The changes in the hypothetical scenario affect most farm scores. As expected, the lower tail shrinks, with a subsequent increase in density in and around the mean and mode, as indicated by the arrows, and the upper end remains anchored at 1.0. However, there is a small reduction in the density just below 1.0 , 

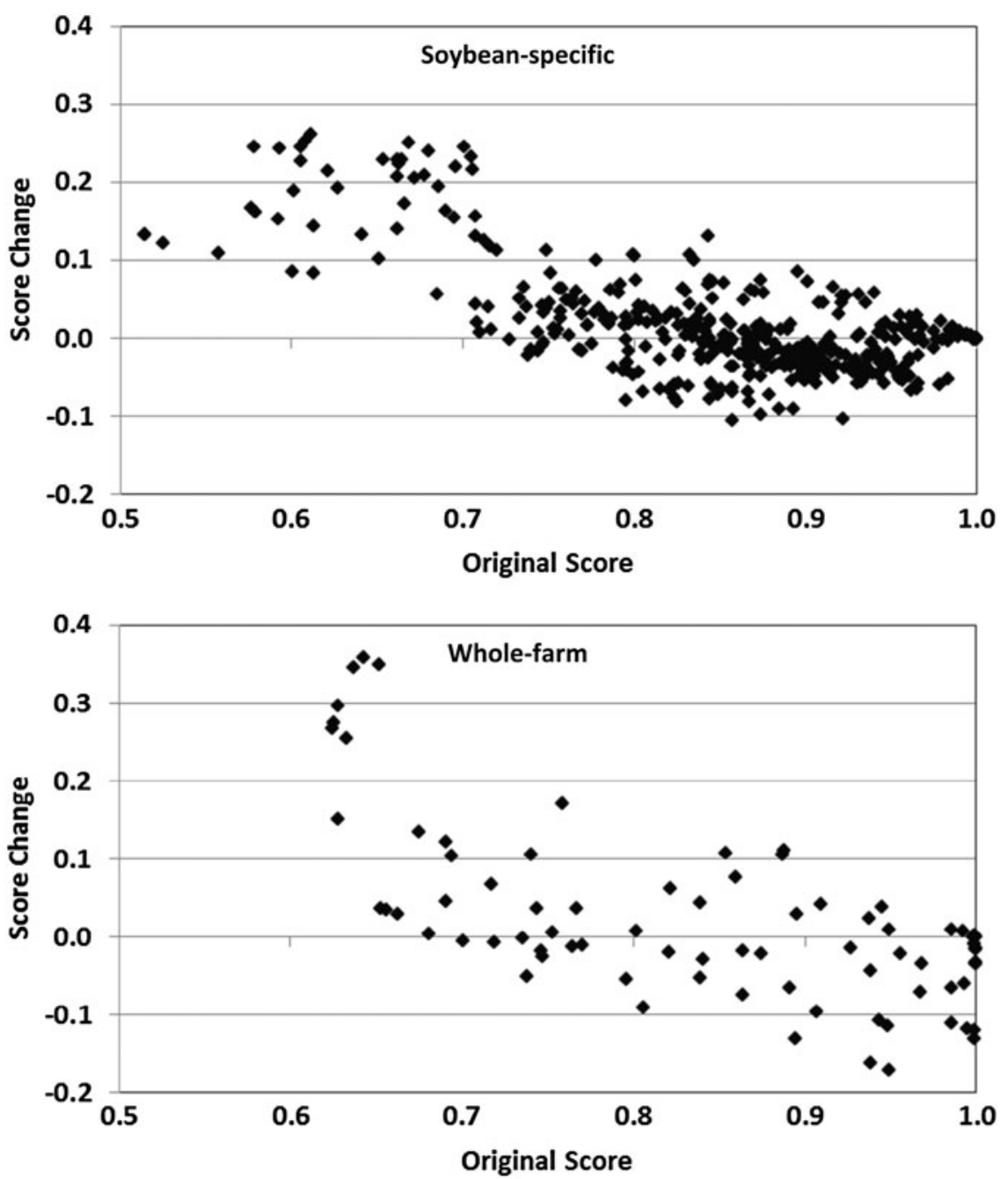

Figure 4. Change in the sustainability assessment score for individual farms under the alternative scenario relative to the current scenario plotted against the original sustainability assessment score for the soybean-specific and the whole-farm sustainability.

implying that farmers with relatively high scores in the current scenario would have slightly reduced scores for this alternative hypothetical scenario. This result occurs because of the relative nature of the scores and weights. Some farmers in the lowest 10th percentile surpass those who previously had relatively high scores after adopting the ten practices, causing those farmers' ranks and scores to decrease. In addition, with certain practices now more widely adopted by farmers, the weights for these practices decrease because these practices do not help differentiate farmers from one another as much as before, although the effect is relatively small.

To better illustrate the impact of the alternative scenario at the individual farm level, Figure 4 plots the sustainability score change for each farm relative to its original score for both the soybean-specific and the whole-farm assessments. As expected, farms with lowest scores for the current scenario had the largest increase in their sustainability score, with this score increase becoming smaller as the original score increased. As a result, both plots in Figure 4 show a strong downward slope. This score increase for those currently with the lowest scores drives the rightward shift of the lower tail in Figure 3. Figure 4 also shows that for many farms, their scores actually decrease, with the magnitude of this decrease generally being larger for those with greater scores for the original scenario. These changes account for the increased density of scores in and around the mean and the slight leftward shift of the upper end of the distribution evident in Figure 3. Finally, Figure 4 shows that there remain a few farms with a score of 1.0 for the current scenario that do not have a score change for the alternative scenario, so that the distribution remains anchored at 1.0 as evident in Figure 3.

\section{Conclusions}

This paper evaluated a data collection process and novel analysis method for calculating a composite sustainability 
scoring system, using it to identify the top practices for improving the sustainability of Midwest soybean production, and illustrated how sustainability scores would change if the lowest performing farmers adopted these top practices. The bottom-up approach used in setting up the sustainability assessment tool required participation of various stakeholders. A key to enhancing grower engagement in sustainability assessment and improvement is the simplicity of the process coupled with providing solid, data-driven results. Extensive voluntary data collection from Midwestern soybean farms in Illinois and Wisconsin is a strong indication of farmers' willingness to participate in such an assessment, as long as they are engaged at the beginning of the process. By identifying and highlighting specific practices growers could implement to increase their sustainability, this analysis gives growers credible feedback and helps advance sustainability systems. Furthermore, the analysis illustrated how targeted policies might impact farmers with lower scores.

It is important to note that this sustainability metric is a relative measure, quantifying the adoption intensity of good farming practices relative to the best farmers in the sample; it is not an absolute measure. To document progress over time, an 'ideal farm' that takes all practices at the most sustainable level could be set up as a frontier benchmark. Farms could then be compared with the ideal farm over time, which would allow the examination of improvement of their sustainability scores (Dong et al., 2015). Since sustainability-practice weights are determined to differentiate farmers from one another, widely used and unused practices receive less weight, even though they may be important for sustainability. As a result, this approach should be combined with other approaches to anchor results with some absolute measures, even as simple as adoption percentages for practices (Knuteson et al., 2014).

In terms of research, an important issue is how to best incorporate measures or estimates of key outcomes such as soil erosion, nutrient leaching or greenhouse gas emissions. Indeed, because farmers commonly mention their desire for a process that connects sustainability results to economic outcomes such as cost or net returns, this is an active area of research (Dong and Mitchell, 2015).

Nevertheless, these results suggest that Midwestern soybean farmers have successfully integrated many best management practices into their farm operations that advance them along the sustainability continuum, but key practices exist that farm leaders currently use and that many farmers could adopt to improve their sustainability. Many of these practices concern improving pest and disease management, with practices to improve crop rotation, to enhance farm economic diversity, and to reduce soil erosion also identified. Educational efforts and other policies should be targeted at increasing adoption of these top whole-farm and soybean-specific practices, as they are currently the key drivers for moving
Midwestern soybean growers forward along the sustainability continuum.

Acknowledgements. We thank the farmers, Extension state specialists, members of the National Initiative for Sustainable Agriculture board members, and other agricultural professionals for providing key input for developing the sustainability self-assessment. We also acknowledge funding from the United Soybean Board that made the National Soybean Sustainability Initiative, as well as from the Illinois Soybean Association, the Wisconsin Soybean Marketing Board, the US Department of Agriculture Specialty Crop Research Initiative, and the Wisconsin Agricultural Experiment Station. Finally, we thank Nicola Wille and Virginia Moore for data analysis assistance.

\section{References}

Alexander, C., Conley, S.P., Dobbins, C.L., Hurt, C.A., and Patrick, G.F. 2007. Marketing practices of Indiana soybean producers. Journal of Extension 45(6):4RIB3.

Beddington, J.R., Asaduzzaman, M., Clark, M.E., Fernández Bremauntz, A., Guillou, M.D., Howlett, D.J.B., Jahn, M.M., Lin, E., Mamo, T., Negra, C., Nobre, C.A., Scholes, R., Van Bo, N., and Wakhungu, J. 2012. What next for agriculture after Durban? Science 335:289-290.

Blend, J.R. and van Ravenswaay, E.O. 1999. Consumer demand for eco-labeled apples: Results from econometric estimation. American Journal of Agricultural Economics 81:1072-1077.

Bunge, J. 2014. Big data comes to the farm, sowing mistrust. Wall Street Journal February 25, 2014. Available at Web site http:// www.wsj.com/articles/SB1000142405270230445090457936928 3869192124 (verified 15 July 2015).

Castle, S. and Naranjo, S.E. 2009. Sampling plans, selective insecticides and sustainability: The case for IPM as 'informed pest management'. Pest Management Science 65:1321-1328.

Conley, S. 2013. NSSI: How Soy Sustainability Can Help You Meet Your Customers' Demands and Expand Your Markets. Plant Management Network Webcast, American Society of Agronomy, Madison, WI. Available at Web site http://www.plantmanagementnetwork.org/edcenter/seminars/ soybean/SoySustainability/ (verified 15 July 2015).

Conley, S.P., Cullen, E., Davis, V., Esker, P., and Laboski, C. 2011a. Soybean yield limiting factors in Wisconsin [online]. University of Wisconsin Extension. Available at Web site http://www.coolbean.info/library/documents/WI_Soybean_ Pocket_Guide.pdf (verified 14 July 2014).

Conley, S.P., Krupke, C., Santini, J., and Shaner, G. 2007. Pest management in Indiana soybean production systems. Journal of Extension 45(4):4RIB8.

Conley, S.P., Pedersen, P., Esker, P., and Gaska, J. 2011 b. Soybean yield and heterodera glycines response to rotation, tillage and source of genetic resistance. Agronomy Journal 103:1604-1609.

Conley, S.P. and Santini, J. 2007. Crop management practices in Indiana soybean production systems [online]. Crop Management doi:10.1094/CM-2007-0104-01-RS. Available 
at Web site https://www.agronomy.org/publications/cm/articles/6/1/2007-0104-01-RS (verified 14 July 2014).

Cooper, W., Seiford, L., Tone, K., and Zhu, J. 2007. Some models and measures for evaluating performances with DEA: Past accomplishments and future prospects. Journal of Productivity Analysis 28:151-163.

Cullen, E., Davis, V., Jensen, B., Nice, G., Renz, M., and Smith, D. 2014. Pest management in Wisconsin field crops -2014 [online]. University of Wisconsin Extension Publication A3646. Available at Web site http://learningstore.uwex.edu/Assets/pdfs/A3646.pdf (verified 14 July 2014).

Davis, V.M. and Conley, S.P. 2011. Characterizing extension value, computer technology, and new media use of midwest soybean growers. Crop Management 10(1). doi:10.1094/ CM-2011-0628-01-RS.

Despotis, D. 2002. Improving the discriminating power of DEA: Focus on globally efficient units. Journal of the Operational Research Society 53:314-323.

Despotis, D. 2005. A reassessment of the human development index via data envelopment analysis. Journal of the Operational Research Society 56:969-980.

Dillman, D.A., Sinclair, M.D., and Clark, J.R. 1993. Effects of questionnaire length, respondent-friendly design, and a difficult question on response rates for occupant-addressed census mail surveys. Public Opinion Quarterly 57:289-304.

Dong, F. and Mitchell, P.D. 2015. Endogenizing sustainability in U.S. corn production: A cost function analysis. In Poster Presented at the Meeting of the Agricultural and Applied Economics Association, San Francisco, CA. Available at Web site http://ageconsearch.umn.edu/bitstream/205428/2/ poster $\% 20$ with $\% 20$ title $\% 20$ page.pdf (verified 15 July 2015).

Dong, F., Mitchell, P., and Colquhoun, J. 2015. Measuring farm sustainability using data envelopment analysis with principal components: The case of Wisconsin cranberry. Journal of Environmental Management 147:175-183.

Dong, F., Mitchell, P.D., Knuteson, D., Wyman, J., Bussan, A.J., and Conley, S. 2012. Whole-farm (cash grain) and soybean specific sustainability assessment. Department of Agricultural and Applied Economics, University of Wisconsin, Madison, WI. Available at Web site http:// www.aae.wisc.edu/pdmitchell/RAFS/SoybeanAssessment. pdf (verified 15 July 2015).

Dyson, R., Allen, R., Camanho, A., Podinovski, V., Sarrico, C., and Shale, E. 2001. Pitfalls and protocols in DEA. European Journal of Operational Research 132:245-259.

Esker, P. and Conley, S.P. 2012. Probability of yield response and breaking-even for soybean seed treatments. Crop Science 52: 351-359.

Evans, M., Hastings, N., and Peacock, B. 2000. Statistical Distributions. 3rd ed. John Wiley and Sons, Hoboken, NJ.

Francis, C. and Youngberg, G. 1990. Sustainable agriculture-an overview. In Francis, C., Flora, C., and King, L. (eds). Sustainable Agriculture in Temperate Zones. John Wiley \& Sons, New York.

Furseth, B.J., Conley, S.P., and Ané, J. 2012. Soybean response to soil rhizobia and seed applied rhizobia inoculants in Wisconsin. Crop Science 52:339-344.

Furseth, B.J., Zhao, Y., Conley, S.P., Martinka, M., and Gaska, J. 2011. Optimum soybean maturity groups for seed yield and quality in Wisconsin [online]. Crop Management doi:10.1094/CM-2011-0622-01-RS. Available at Web site https:/www.agronomy.org/publications/cm/pdfs/10/1/2011-062201-RS (verified 13 June 2014).

Garnett, T., Appleby, M.C., Balmford, A., Bateman, I.J., Benton, T.G., Bloomer, P., Burlingame, B., Dawkins, M., Dolan, L., Fraser, D., Herrero, M., Hoffmann, I., Smith, P., Thornton, P.K., Toulmin, C., Vermeulen, S.J., and Godfray, H.C.J. 2013. Sustainable intensification in agriculture: Premises and policies. Science 341:33-34.

Gibbs, H.K., Rausch, L., Munger, J., Schelly, I., Morton, D.C., Noojipady, P., Soares-Filho, B., Barreto, P., Micol, L., and Walker, N.F. 2015. Brazil's soy moratorium. Science 347: 377-378.

Gliessman, S. 1998. An Ecological Definition of Sustainable Agriculture. Principles of agroecology and sustainability. Available at Web site http://agroecology.org/Principles_Def. html (verified 21 July 2015).

Hanna, S., Conley, S.P., Shaner, G., and Santini, J. 2008. Fungicide application timing and row spacing effect on soybean canopy penetration and grain yield. Agronomy Journal 100:1488-1492.

Hatefi, S.M. and Torabi, S.A. 2010. A common weight MCDADEA approach to construct composite indicators. Ecological Economics 70:114-120.

Hotelling, H. 1933. Analysis of a complex of statistical variables into principal components. Journal of Educational Psychology 24:417-441.

Iowa State University Extension. 2008. Soybean drying and storage. PM-1623, Iowa State University Extension, Ames, IA. Available at Web site http://www.extension.iastate.edu/ grain/files/Migrated/PM1636.pdf (verified 15 July 2015).

Johnson, W.G., Gibson, K.D., and Conley, S.P. 2007. Does weed size matter? An Indiana grower perspective about weed control timing. Weed Technology 21:542-546.

Jolliffe, I.T. 2002. Principal Component Analysis. 2nd ed. Springer, New York.

Knuteson, D., Conley, S., Mitchell, P., and Dong, F. 2014. Illinois/ Wisconsin soybean sustainability survey results. Department of Agronomy, University of Wisconsin, Madison, WI. Available at Web site http://www.coolbean.info/pdf/soybean_re search/national_sustainability_initiative/SoybeanSurveyResults_ 2013_FINAL.pdf (verified 15 July 2015).

Laboski, C. and Peters, J. 2012. Nutrient application guidelines for field, vegetable, and fruit crops in Wisconsin [online]. University of Wisconsin Extension Publication A2809. Available at Web site http://learningstore.uwex.edu/assets/ pdfs/A2809.pdf (verified 14 July 2014).

Labuschagne, C., Brent, A.C., and van Erck, R.P.G. 2005. Assessing the sustainability performances of industries. Journal of Cleaner Production 13:373-385.

Lendle, A. and Schaus, M. 2010. Sustainability criteria in the EU Renewable Energy Directive: Consistent with WTO rules? International Centre for Trade and Sustainable Development, Information Note No. 2, Geneva, CH. Available at Web site http://www.ictsd.org/sites/default/files/research/2011/12/sustainability-criteria-in-the-eu-renewable-energy-directive-consistentwith-wto-rules.pdf (verified 15 July 2015).

Marburger, D., Conley, S.P., Esker, P., MacGuidwin, A., and Smith, D. 2014. Relationship between Fusarium virguliforme and Heterodera glycines in Wisconsin fields [online]. Plant Health Progress. doi:10.1094/PHP-RS-13-0107. Available at Web site http://www.plantmanagementnetwork.org/php/elements/sum2.aspx?id=10738 (verified 14 July 2014). 
Montgomery, D.R. 2007. Soil erosion and agricultural sustainability. Proceedings of the National Academy of Sciences USA 104:13268-13272.

Murphy, F., McDonnell, K., and Fagan, C.C. 2014. Sustainability and environmental issues in food processing. In Clark, S., Jung, S., and Lamsal, B. (eds). Food Processing: Principles and Applications. 2nd ed. John Wiley \& Sons, Hoboken, NJ. p. 207-232.

National Initiative for Sustainable Agriculture. 2014a. NISA sustainability outcomes, example indicators and metrics, and documentation parameters. Available at Web site http:// fieldrise.com/wp-content/uploads/2014/10/NISA-ExpectedAssessment-Outcomes.pdf (verified 20 January 2015).

National Initiative for Sustainable Agriculture. 2014b. NISA cash grain whole farm and soybean sustainability assessment. Available at Web site http://www.surveygizmo.com/s3/1642373/ NISA-Cash-Grain-Whole-Farm-and-Soybean-SustainabilityAssessment (verified 20 January 2015).

National Research Council. 2010. Toward Sustainable Agricultural Systems in the 21st Century. National Academies Press, Washington, DC.

National Sustainable Soybean Initiative. 2014. NISA cash grain soybean specific protocol. Available at Web site http://www.sur veygizmo.com/s3/776277/NSSI-CASH-GRAIN-SOYBEANSPECIFIC-PROTOCOL (verified 20 January 2015).

Nimon, W. and Beghin, J. 1999. Are eco-labels valuable? Evidence from the apparel industry. American Journal of Agricultural Economics 81:801-811.

Nivens, H.D., Kastens, T.L., and Dhuyvetter, K.C. 2002. Payoffs in farm management: How important is crop marketing. Journal of Agricultural and Applied Economics 34:193-204.

Nunamaker, T. 1985. Using data envelopment analysis to measure the efficiency of non-profit organization: A critical evaluation. Managerial and Decision Economics 6:50-58.

Onozaka, Y. and McFadden, D.T. 2011. Does local labeling complement or compete with other sustainable labels? A conjoint analysis of direct and joint values for fresh produce claims. American Journal of Agricultural Economics 93:693-706.

Pearson, K. 1901. On lines and planes of closest fit to systems of points in space. Philosophical Magazine 2:559-572.

Pennings, J.M.E., Irwin, S.H., and Good, D.L. 2002. Surveying farmers: A case study. Review of Agricultural Economics 24:266-277.

Pittelkow, C.M., Liang, X., Linquist, B.A., van Groenigen, K.J., Lee, J., Lundy, M.E., van Gestel, N., Six, J., Venterea, R.T., and van Kessel, C. 2015. Productivity limits and potentials of the principles of conservation agriculture. Nature 517: 365-368.

Rincker, K., Nelson, R., Specht, J., Sleper, D., Cary, T., Cianzio, S.R., Casteel, S., Conley, S.P., Chen, P., Davis, V., Fox, C., Graef, G., Godsey, C., Holshouser, D., Jiang, G., Kantartzi, S.K., Kenworthy, W., Lee, C., Mian, R., McHale, L., Naeve, S., Orf, J., Poysa, V., Schapaugh, W., Shannon, G., Uniatowski, R., Wang, D., and Diers, B. 2014. Genetic improvement of US soybean in maturity groups II, III, and IV. Crop Science 54:1-14.

Robinson, A.P., Conley, S.P., Volenec, J.J., and Santini, J.B. 2009. Analysis of high yielding, early-planted soybean in Indiana. Agronomy Journal 101:131-139.
Robinson, L.W., Ericksen, P.J., Chesterman, S., and Worden, J.S. 2015. Sustainable intensification in drylands: What resilience and vulnerability can tell us. Agricultural Systems 135: 133-140.

Rowntree, S., Suhre, J.J., Weidenbenner, N., Wilson, E., Davis, V., Naeve, S., Casteel, S., Diers, B., Esker, P., Specht, J., and Conley, S.P. 2013. Genetic gain x management interactions in soybean: I. planting date. Crop Science 53:1-11.

Rowntree, S., Suhre, J.J., Wilson, E., Davis, V., Casteel, S., Diers, B., Esker, P., and Conley, S.P. 2014. Physiological and phenological responses of historical soybean cultivar releases to earlier planting. Crop Science 54:804-816.

Schulte, E., Walsh, L., Kelling, K., Bundy, L., Bland, W., Wolkowski, R., Peters, J., and Sturgul, S. 2005. Management of Wisconsin soils [online]. UW-Extension publication A3588, 5th edition. Available at Web site http://www.soils. wisc.edu/extension/pubs/A3588.pdf (verified 14 July 2014).

Sustainable Agriculture Research and Education (SARE). 1997. Exploring sustainability in agriculture: Ways to enhance profits, protect the environment and improve quality of life. Available at Web site http://www.sare.org/Learning-Center/ SARE-Program-Materials/National-Program-Materials/Whatis-Sustainable-Agriculture (verified 21 July 2015).

Sustainable Agriculture Research and Education Program. 2015. What Is Sustainable Agriculture? University of California, Davis, CA. Available at Web site http://www.sarep.ucdavis. edu/about-sarep/def/ (verified 21 July 2015).

Teisl, M.F., Roe, B., and Levy, A.S. 1999. Eco-Certification: Why it may not be a 'field of dreams.' American Journal of Agricultural Economics 81:1066-1071.

The Royal Society. 2009. Reaping the Benefits: Science and the Sustainable Intensification of Global Agriculture. Available at Web site https://royalsociety.org/ /media/Royal_Society_ Content/policy/publications/2009/4294967719.pdf (verified 21 July 2015).

Tillman, D., Cassman, K.G., Matson, P.A., Naylor, R., and Polasky, S. 2002. Agricultural sustainability and intensive production practices. Nature 418:671-677.

Tillman, D., Wedin, D., and Knops, J. 1996. Productivity and sustainability influenced by biodiversity in grassland ecosystems. Nature 379:718-720.

United Nations. 1987. Report of the World Commission on Environment and Development: Our Common Future. Transmitted to the General Assembly as an Annex to document A/42/427-Development and International Cooperation: Environment, 1987. Available at Web site http:// www.un-documents.net/wced-ocf.htm (verified 21 July 2015).

U.S. Department of Agriculture (USDA). 2014. 2012 Census of Agriculture. Table 37. Specified Crops by Acres Harvested [online]. Washington, DC: USDA. Available at Web site http://www.agcensus.usda.gov/Publications/2012/Full_Report/ Volume_1,_Chapter_1_State_Level/Illinois/st17_1_037_037. pdf (verified 14 July 2014).

U.S. Department of Agriculture Natural Resource Conservation Service (USDA-NRCS). 2010. 2007 national resources inventory: Soil erosion on cropland. USDA-NRCS, Washington, DC. Available at Web site http://www.nrcs.usda.gov/ Internet/FSE_DOCUMENTS/nrcs143_012269.pdf (verified 15 July 2015). 